
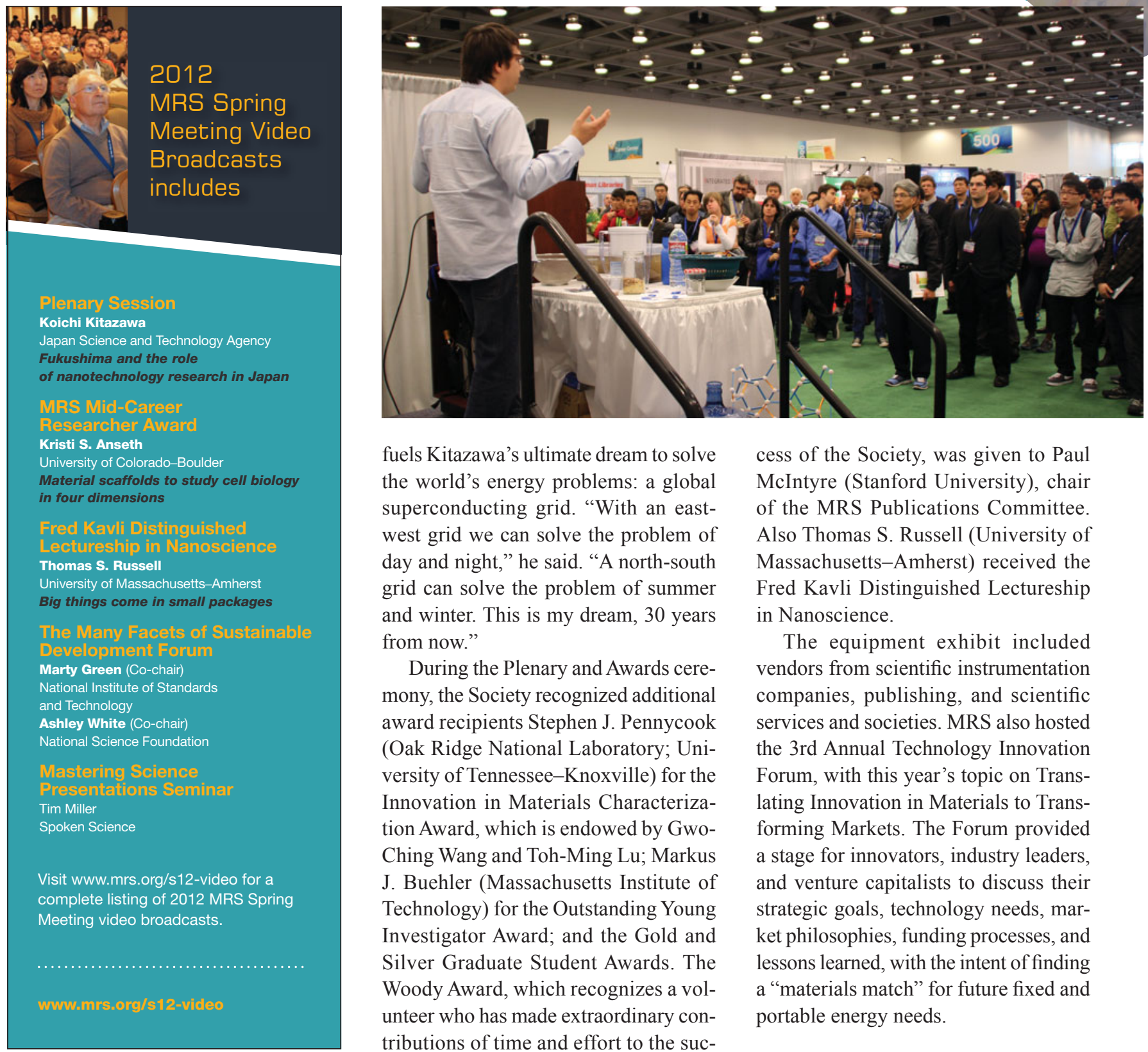

fuels Kitazawa's ultimate dream to solve the world's energy problems: a global superconducting grid. "With an eastwest grid we can solve the problem of day and night," he said. "A north-south grid can solve the problem of summer and winter. This is my dream, 30 years from now."

During the Plenary and Awards ceremony, the Society recognized additional award recipients Stephen J. Pennycook (Oak Ridge National Laboratory; University of Tennessee-Knoxville) for the Innovation in Materials Characterization Award, which is endowed by GwoChing Wang and Toh-Ming Lu; Markus J. Buehler (Massachusetts Institute of Technology) for the Outstanding Young Investigator Award; and the Gold and Silver Graduate Student Awards. The Woody Award, which recognizes a volunteer who has made extraordinary contributions of time and effort to the suc- cess of the Society, was given to Paul McIntyre (Stanford University), chair of the MRS Publications Committee. Also Thomas S. Russell (University of Massachusetts-Amherst) received the Fred Kavli Distinguished Lectureship in Nanoscience.

The equipment exhibit included vendors from scientific instrumentation companies, publishing, and scientific services and societies. MRS also hosted the 3rd Annual Technology Innovation Forum, with this year's topic on Translating Innovation in Materials to Transforming Markets. The Forum provided a stage for innovators, industry leaders, and venture capitalists to discuss their strategic goals, technology needs, market philosophies, funding processes, and lessons learned, with the intent of finding a "materials match" for future fixed and portable energy needs.

\title{
Preview: XXI International Materials Research Congress 2012
}

\author{
August 12-17, 2012 Cancun, Mexico \\ www.mrs-mexico.org.mx/imrc2012 \\ www.mrs.org/imrc2012
}

he XXI International Materials Research Congress (IMRC) 2012, to be held on August 12-17, 2012 in Cancun, Mexico, is a joint meeting of the Sociedad Mexicana de Materiales (SMM) and the Materials Research Society (MRS). The Meeting Chairs are Orlando Auciello of Argonne National
Laboratory, USA; Sandra Rodil Posada of the Nacional Autónoma de México (UNAM), Mexico; J. Gerardo Cabañas Moreno of the National Polytechnic Institute, Mexico; and Francesco Stellacci of École Polytechnique Fédérale de Lausanne, Switzerland; and the chair of de Materiales A.C MRS the Congress is Sergio Mejia Rosales of Universidad Autónoma de Nuevo Léon. The Congress will feature 27 symposia, some of which will be co-organized by SMM and MRS; oral and poster 
presentations; tutorials; and an equipment exhibition.

Among the plenary speakers are Nobel laureate Ada Yonath (Weizmann Institute Rehovot, Israel), presenting a lecture on "The ribosome: An energetic cellular nano machine"; Monica Olvera de la Cruz (UNAM), "Platonic and Archimedean geometries in elastic membranes"; Manish Chhowalla (Rutgers University, USA), "Solution processable two-dimensional materials for energy applications"; Carlos A. Paz de Araujo (University of Colorado, USA), "Materials science and device technology from laboratory to real world applications"; and Bao-Lian Su (University of Namur, Belgium), "Living hybrid materials for green energy production, environmental remediation and smart cell-therapy." During a Science Luncheon, Luis F. Rodríguez (UNAM) will present a talk on "Radio astronomy: The achievements and the challenges."

The list of symposia is as follows (*designates symposia co-organized by SMM and MRS).

\section{Nano Science and Technology}

1A: Low-Dimensional Bismuth-based Materials*

1B: Nanostructured Carbon Materials for MEMS/NEMS and Nanoelectronics*
1C: Nanostructured Materials and Nanotechnology

\section{Materials Characterization}

2A: The Role of Surfaces and Interfaces in Materials Processes*

2B: Novel Characterization Methods for Biological Systems*

2C: Quantitative Measurements with Atomic Force Microscopy in Fluids*

2D: Structural and Chemical Characterization of Metals, Alloys, and Compounds

\section{Materials for Energy Production}

3A: Materials for Polymer Electrolyte Membrane Fuel Cells*

3B: Photocatalytic and Photoelectrochemical Nanomaterials for Sustainable Energy*

3C: Photovoltaics, Solar Energy Materials, and Technologies

3D: New Catalytic Materials

3E: Renewable Energy and Sustainable Development

\section{Biomaterials}

4A: Nanotechnology-enhanced Biomaterials and Biomedical Devices*

4B: Biomaterials for Medical Applications

\section{Polymers}

5A: Soft Responsive Materials*
5B: New Trends in Polymer Chemistry and Characterization

\section{Electronics and Photonics}

6A: Organic Materials for Electronics and Photonics*

6B: Low-Dimensional Semiconductor Structures*

6C: Advances in Semiconducting Materials

6D: Materials and Devices for LargeArea Electronics*

\section{Fundamental Materials Science}

7A: Advances in Computational Materials Science

7B: Concrete with Smart Additives and Supplementary Cementitious Materials*

7C: NACE: Corrosion and Metallurgy

7D: Advanced Structural Materials

7E: Interfaces, Structure, and Domain Engineering in Ferroic Systems*

7F: Solid-State Chemistry of Functional Inorganic Materials*

\section{General}

8A: Strategies for Academy-Industry Relationship

For additional information on the Congress, access www.mrs-mexico.org.mx/ imrc2012.

\section{Conference on combinatorial materials S\&T to be held in October} http://combi2012.com

$\mathbf{T}$ he 7 th International Conference on Combinatorial Materials Science and Technology will be held on October 21-24, 2012 in Charleston, South Carolina. The workshop is devoted to combinatorial materials, attracting scientists worldwide. The conference will have representatives from academia, government laboratories, and industry. The conference website with the tentative sched- ule and names of the invited speakers are available at http://combi2012.com. The conference is endorsed by the Materials Research Society.

The focus of this workshop will be multifold. First, it aims to foster international collaboration by inviting participants from a wide variety of backgrounds. Topically, there will be an emphasis on the contributions of both computational and experimental combinatorial materials science to the fields of energy, sensing, electronic materials, and heterogeneous catalysis. Additionally, emphasis will be placed on balancing academic and industrial contributions to provide perspectives on how highthroughput methodologies are brought to bear on questions of scientific and engineering importance.

\section{wwW.mrs.org}

